BMJ Open Sport \& Exercise Medicine

\title{
Evaluation of spine MRIs in athletes participating in the Rio de Janeiro 2016 Summer Olympic Games
}

Michael S Wasserman, ${ }^{1}$ Ali Guermazi, ${ }^{1}$ Mohamed Jarraya, ${ }^{2}$ Lars Engbretsen, $, 3,5$ Mohamad AbdelKader, ${ }^{1}$ Frank W Roemer, ${ }^{1,6}$ Daichi Hayashi, ${ }^{1,7}$ Michel D Crema, ${ }^{1,8,9}$ Asim Z Mian ${ }^{1}$

To cite: Wasserman MS, Guermazi A, Jarraya M, et al. Evaluation of spine MRIs in athletes participating in the Rio de Janeiro 2016 Summer Olympic Games. BMJ Open Sport \& Exercise Medicine 2018;4:e000335. doi:10.1136/ bmjsem-2017-000335

- Additional material is published online only. To view please visit the journal online (http://dx.doi.org/10.1136/ bmjsem-2017-000335)

Accepted 3 February 2018
Check for updates

For numbered affiliations see end of article.

Correspondence to Dr Michael S Wasserman; michael.wasserman@bmc.org

\section{ABSTRACT}

Background/aim In high-level Olympic athletes, many spinal pathologies arise from overuse, while others are the result of acute injury. Our aim is to analyse the epidemiology of spinal pathologies detected on MRI in athletes participating in the 2016 Rio de Janeiro Summer Olympics.

Methods In this retrospective study, all spine MRIs performed during the 2016 Rio Games were analysed. Descriptive data from the MRIs were tabulated and analysed for disc degeneration, spinal canal and/or neural foraminal narrowing, and acute/chronic fractures. Data were analysed by sport, continent of origin, age and sex. Results of 11274 athletes participating in the Olympic games, 100 received spine MRI. Fifty-two of the $100(52 \%)$ athletes who received cervical, thoracic and/or lumbar spine MRI showed moderate to severe spinal disease. The highest sport-specific incidence of moderate to severe spine disease was seen in aquatic diving athletes $(67 \%$, 3 per 100 divers). Weightlifting had the second highest sport-specific incidence of spine disease $(67 \%, 1.5 \mathrm{per}$ 100 weightlifters). Athletics used the most spine MRIs (31 of $107 \mathrm{MRIs}, 29 \%$ ). European athletes had more spine MRls than all other continents combined (55 of 107 MRls, $51 \%)$. Athletes over 30 years old had the highest rate of moderate to severe spine disease on MRI (24 of 37 athletes $>30$ years old, $65 \%$ ).

Conclusions A high number of the world's premier athletes demonstrated moderate to severe spine disease on MRI during the 2016 Summer Olympics, including moderate/severe degenerative disc changes with varying degrees of disc bulges and herniations.

\section{INTRODUCTION}

The 2016 Summer Olympics were hosted by Rio de Janeiro, Brazil, from 5 to 21 August 2016. A total of 11274 athletes from 207 National Olympic Committees (NOCs) competed in 28 sports and 306 sporting events. ${ }^{1}$

Overall, 1101 injuries in $8 \%$ of the athletes were reported during the Games. ${ }^{2}$ The incidence of injury was lower than at other recent Olympics: $10 \%$ at the 2008 Beijing Games, $11 \%$ at the 2010 Vancouver Winter Olympics, $11 \%$ at the 2012 London Games and
What are the new findings?

Fifty-two moderate to severe spine injuries were reported on spine MRI during the Rio de Janeiro 2016 Summer Olympic Games, with the highest incidence of spine injuries seen in women and in athletes over 30 years old.

- While athletics used spine MRI the most of any sport, diving had the highest sport-specific incidence of moderate to severe spinal pathology.

- Most moderate to severe spine injuries seen in the Rio de Janeiro 2016 Summer Olympic Games involved the lumbar spine.

How might it impact clinical practice in the near future?

Recognition of the high number of moderate to severe spine injuries occurring in Olympic-calibre athletes may lead to spine-conscious training, routines and manoeuvres during competition in order to prevent the development and progression of acute and chronic spinal pathologies.

$12 \%$ at the 2014 Sochi Winter Olympics. ${ }^{2-6}$ Forty per cent of the injuries were estimated to be severe enough to limit competition or training. ${ }^{2}$ Of these, $71 \%$ occurred acutely, whereas $27 \%$ were secondary to overuse. ${ }^{2}$ The three most commonly reported mechanisms of injury were contact with another athlete, non-contact trauma and overuse injury with gradual onset. $^{2}$

MRI is especially useful to evaluate soft tissue and ligamentous injuries and to evaluate for bone marrow oedema and contusion in the spine. Loss of disc signal intensity, loss of disc height and presence of disc displacement are most commonly seen at the L5-S1 level. ${ }^{7}$ These pathologies are easily detected on MRI.

The purpose of this study is to investigate the various pathologies that affect the spine in high-level athletes by evaluating the MRIs 
of the spine in athletes who participated in the 2016 Rio Summer Olympics.

\section{METHODS}

This is a retrospective analysis of the patient information from the IOC athlete database and imaging data from the Radiological Information System and Picture Archiving Communications System of the Rio Summer Olympics. Medical and imaging services were open for 32 days including from the opening of the Olympic Village on 24 July 2016 to its closing on 24 August 2016. NOC medical teams reported the daily occurrence (or non-occurrence) of injuries on a standardised medical report form. We retrieved the same information on all athletes treated for injuries in the polyclinic and all other medical venues by the medical staff of the Rio Organising Committee. We used the athlete accreditation number to control for injuries treated by both groups. With duplicates, we retained the NOC data. Our study and intent to publish the data were approved by the IOC (R2C10).

\section{Confidentiality and ethical approval}

Our retrospective study was reviewed by the Medical Research Ethics Committee of the South-Eastern Norway Regional Health Authority and was exempted from Ethics Committee approval. Informed consent was waived since all data in our epidemiological study were anonymised and unidentifiable. We obtained approval from the IOC to use anonymised imaging and demographic data for publication. An additional institutional review board (IRB) approval was obtained from Boston University. Data were collected, stored and analysed in strict compliance with data protection and athlete confidentiality.

\section{Data collection}

Diagnostic imaging was performed through the official IOC polyclinic within the Olympic Village, using 3T Discovery MR750w and 1.5T Optima 450MRw MRI scanners (all machines from GE Healthcare, Brazil). Protocols consisted of three planes of acquisition in the sagittal plane for the cervical, thoracic and lumbosacral spine which included T1-weighted, T2-weighted and short tau inversion recovery. There were two planes of acquisition in the axial plane for the cervical and lumbar spine with two-dimensional multiple echo recombined gradient echo (2D MERGE) and isotropic 3D CUBE T2-weighted for the cervical spine and T1-weighted and T2-weighted for the lumbar spine. For the thoracic spine, there was only one axial plane consisting of 2D MERGE.

\section{Imaging interpretation}

All cervical, thoracic and lumbosacral spine MRI examinations performed were independently reviewed and all spine pathologies were documented by a board-certified neuroradiologist (AZM) with 13 years of experience in orthopaedic and traumatic spine injuries assessment. For the purposes of this study, a positive spine MRI was defined as demonstrating moderate to severe disc degeneration (Pfirrmann grade IV or V), canal or neural foraminal narrowing. ${ }^{8}$ These findings were considered chronic spine pathology. Muscle injury, ligamentous injury and vertebral compression deformity with bone marrow oedema were considered acute spinal pathology. Muscle and ligamentous injuries were defined as these soft tissues demonstrating hyperintensity on the T2-weighted fat-suppressed images. ${ }^{9}$ Spondylolysis and spondylolisthesis with and without bone marrow oedema/stress reaction of the pars interarticularis were considered acute and chronic spine pathology, respectively.

The Pfirrmann classification system is used to grade lumbar disc degeneration. ${ }^{10}$ In this system, a T2-weighted sequence is used to grade lumbar disc degeneration. In grades I-III, disc height is normal. The disc is homogeneous in grade I but is heterogeneous in grade II. The distinction between the nucleus and annulus becomes unclear in grade III. There is inhomogeneous disc signal with height mildly to moderately decreased in grade IV. In grade V, the disc space is collapsed. In this study, these criteria were extended to the evaluation of the cervical and thoracic spine. Additionally, we considered Pfirrmann's grades I-III as mild degenerative disc disease since there was no loss of disc space height. Pfirrmann's grade IV was considered moderate due to reduced disc space height and grade $\mathrm{V}$ was considered severe due to collapsed disc space.

\section{RESULTS}

\section{Demographics and spine MRI utilisation}

Table 1 shows the incidence of all positive spine MRIs stratified by sport. The 2016 Rio Games had 11274 athletes participating, 100 of whom $(0.9 \%)$ received an MRI of the spine during the Olympics. Fifty-two of these athletes $(52 \%)$ had positive spine pathology on imaging. Five athletes had more than one spine MRI, including two who had cervical, thoracic and lumbar spine MRIs, two who had cervical and lumbar spine MRIs and one who had cervical and thoracic spine MRIs. In total, 107 spine MRIs were performed.

Positive spine MRI findings included moderate/ severe disc degeneration (Pfirrmann's classification type IV or V), moderate/severe spinal canal and/or neural foraminal narrowing, muscle injury, ligamentous injury, spondylolysis, vertebral fracture or pars interarticularis oedema.

Table 2 stratifies the spine MRIs by event and shows that athletics had the highest use of spine MRI. Thirty of the $80(38 \%)$ lumbar spine MRIs were for athletes participating in athletics. Judo had the second highest utilisation of spine MRIs with six lumbar spine MRIs and three cervical spine MRIs. Gymnastics, diving, boxing and weightlifting each accounted for more than six spine MRIs.

There were no spine MRIs acquired in aquatics-open water swimming, aquatics—synchronised swimming, basketball, canoe-slalom, cycling-BMX (bicycle 
Table 1 Incidence of positive spine MRIs in athletes by sport

\begin{tabular}{|c|c|c|c|c|c|}
\hline Sport & Total athletes & $\begin{array}{l}\text { Athletes receiving } \\
\text { spine MRIs }\end{array}$ & Positive spine MRIs & $\begin{array}{l}\text { Frequency (positive } \\
\text { MRIs/all spine MRIs) }\end{array}$ & $\begin{array}{l}\text { Incidence } \\
\text { (positive MRIs/total } \\
\text { athletes } \times 100 \text { ) }\end{array}$ \\
\hline Aquatics-diving & 135 & 6 & 4 & 67 & 3.0 \\
\hline Aquatics-swimming & 901 & 4 & 2 & 50 & 0.2 \\
\hline Aquatics-water polo & 258 & 1 & 1 & 100 & 0.4 \\
\hline Archery & 128 & 1 & 1 & 100 & 0.8 \\
\hline Athletics & 2367 & 31 & 15 & 48 & 0.6 \\
\hline Badminton & 172 & 1 & 0 & 0 & 0 \\
\hline Beach volleyball & 96 & 1 & 0 & 0 & 0 \\
\hline Boxing & 286 & 4 & 1 & 25 & 0.4 \\
\hline Canoe-sprint & 248 & 1 & 0 & 0 & 0 \\
\hline Cycling-mountain biking & 80 & 1 & 1 & 100 & 1.3 \\
\hline Equestrian & 200 & 1 & 0 & 0 & 0 \\
\hline Fencing & 204 & 2 & 1 & 50 & 0.5 \\
\hline Football & 503 & 2 & 1 & 50 & 0.2 \\
\hline Gymnastics & 322 & 6 & 1 & 17 & 0.3 \\
\hline Handball & 335 & 2 & 2 & 100 & 0.6 \\
\hline Hockey & 384 & 3 & 2 & 67 & 0.5 \\
\hline Judo & 390 & 8 & 5 & 63 & 1.3 \\
\hline Rowing & 546 & 3 & 1 & 33 & 0.2 \\
\hline Rugby & 291 & 1 & 1 & 100 & 0.3 \\
\hline Sailing & 380 & 2 & 2 & 100 & 0.5 \\
\hline Shooting & 390 & 3 & 1 & 33 & 0.3 \\
\hline Table tennis & 172 & 2 & 1 & 50 & 0.6 \\
\hline Tennis & 199 & 2 & 1 & 50 & 0.5 \\
\hline Triathlon & 109 & 1 & 1 & 100 & 0.9 \\
\hline Volleyball & 288 & 3 & 1 & 33 & 0.3 \\
\hline Weightlifting & 256 & 6 & 4 & 67 & 1.6 \\
\hline Wrestling & 349 & 2 & 2 & 100 & 0.6 \\
\hline Others & 1285 & 0 & 0 & 0 & 0 \\
\hline Total & 11274 & 100 & 52 & 52 & 0.5 \\
\hline
\end{tabular}

motocross), cycling-road, cycling-track, golf, modern pentathlon or taekwondo.

Table 3 shows the incidence of positive spine MRIs stratified by sport in the 5089 female athletes. Fifty-five $(1.1 \%)$ received a spinal MRI during the Games and 25 (45\%) of the MRIs showed moderate to severe spinal pathology. Sports with the highest number of positive spinal MRIs in female athletes (excluding sports with only one MRI) included judo ( 1 of $2,50 \%$ ), athletics (11 of $22,50 \%$ ), weightlifting (2 of $3,67 \%$ ) and hockey (2 of $2,100 \%$ ).

Table 3 shows the incidence of positive spine MRIs stratified by sport in the 6185 male athletes. Forty-five $(0.7 \%)$ received a spinal MRI during the Games, and 26 (58\%) of the MRIs showed moderate to severe spinal pathology. Sports with the highest number of positive spinal MRIs in male athletes (excluding sports with only one MRI) included athletics ( 4 of 9, 44\%), swimming ( 1 of 2, $50 \%$ ), judo ( 4 of $6,67 \%$ ), weightlifting (2 of $3,67 \%)$, tennis (2 of $2,100 \%$ ), diving (2 of 2, 100\%) and wrestling (2 of 2, $100 \%)$.

Table 4 shows that of 107 MRIs acquired, 55 (51\%) were performed on European athletes, the most of any continent. European athletes accounted for 37 of $82(45 \%)$ lumbar spine MRIs, 12 of $21(57 \%)$ cervical spine MRIs and all $6(100 \%)$ of the thoracic spine MRIs. Africa $(19,18 \%)$, the Americas $(16,15 \%)$, Asia (12, $11 \%)$ and Oceania $(5,5 \%)$ had the next highest utilisation of spine MRI during the Olympics. Athletes on the Refugee Olympic Team had no MRIs of the spine.

Online supplementary table S1 shows the incidence of positive spine MRIs stratified by sport in the 611 athletes less than 20 years old. Seven $(1.15 \%)$ received a spinal MRI during the Games, and only one (14\%) showed 
Table 2 Utilisation of each type of spine MRI by sport

\begin{tabular}{lccc}
\hline Sport & Cervical & Thoracic & Lumbar \\
\hline Aquaticsdiving & 1 & 1 & 4 \\
\hline Aquatics-swimming & 1 & 0 & 3 \\
\hline Aquatics-water polo & 1 & 0 & 0 \\
\hline Archery & 0 & 0 & 1 \\
\hline Athletics & 1 & 1 & 30 \\
\hline Badminton & 0 & 0 & 1 \\
\hline Beach volleyball & 0 & 0 & 1 \\
\hline Boxing & 1 & 1 & 4 \\
\hline Canoe-sprint & 1 & 0 & 0 \\
\hline Cycling-mountain biking & 0 & 0 & 1 \\
\hline Equestrian & 0 & 0 & 1 \\
\hline Fencing & 1 & 0 & 1 \\
\hline Football & 1 & 0 & 1 \\
\hline Gymnastics & 2 & 1 & 4 \\
\hline Handball & 0 & 0 & 2 \\
\hline Hockey & 2 & 0 & 1 \\
\hline Judo & 3 & 0 & 6 \\
\hline Rowing & 0 & 0 & 3 \\
\hline Rugby & 0 & 0 & 1 \\
\hline Sailing & 1 & 0 & 1 \\
\hline Shooting & 2 & 1 & 2 \\
\hline Table tennis & 0 & 1 & 1 \\
\hline Tennis & 1 & 0 & 1 \\
\hline Triathlon & 0 & 0 & 1 \\
\hline Volleyball & 0 & 0 & 3 \\
\hline Weightlifting & 0 & 0 & 6 \\
\hline Wrestling & 21 & $\mathbf{6}$ & $\mathbf{8 0}$ \\
\hline Total & & & \\
\hline & 0 & 0 \\
\hline
\end{tabular}

moderate to severe spinal pathology. The one athlete less than 20 years old who received a spine MRI participated in weightlifting and demonstrated moderate/severe disc disease at L5-S1, disc protrusions at L4-5 and L5-S1 and mild spinal canal and neural foraminal stenosis at these levels.

Online supplementary table S1 also shows the incidence of positive spine MRIs stratified by sport in the 7753 athletes between the ages of 20-29 years old. Fifty-six $(0.7 \%)$ received a spinal MRI and $27(48 \%)$ of the MRIs showed moderate to severe spinal pathology. The sports with the highest number of MRIs with moderate to severe spinal pathology in this age group included athletics (10 of $21,48 \%$ ), diving (3 of $5,60 \%$ ), weightlifting (2 of 2 , $100 \%)$ and judo (2 of $4,50 \%)$.

Online supplementary table $\mathrm{S} 1$ shows the incidence of positive spine MRIs stratified by sport in the 2910 athletes over 30 years old. Thirty-seven $(1.27 \%)$ received a spinal MRI and 24 (65\%) of the MRIs showed moderate to severe spinal pathology. The sports with the highest number of
MRIs with moderate to severe spinal pathology in this age group included athletics ( 5 of $9,56 \%$ ), judo (3 of $4,75 \%$ ) and handball (2 of $2,100 \%$ ).

\section{Chronic spinal pathology}

Thirty-seven of the 107 spine MRIs (35\%) performed demonstrated moderate to severe degenerative disc disease per the Pfirrmann classification system (types IV and $\mathrm{V}$ degenerative disc disease) (figure 1). Thirty-one of the $37(84 \%)$ spine MRIs with moderate to severe degenerative disc disease were of the lumbar spine, while $6(16 \%)$ were of the cervical spine. No athletes receiving MRI of the thoracic spine demonstrated moderate or severe degenerative disc disease. Athletics accounted for the majority of the positive scans that showed moderate to severe degenerative disc disease, with 12 of the $30(40 \%)$ athletes having positive lumbar spine MRIs.

Ten of the spine MRIs (9\%) demonstrated moderate to severe canal narrowing (figure 1). Six of the $10(60 \%)$ scans were of the lumbar spine, while four $(40 \%)$ were of the cervical spine. Sports with spine MRIs showing moderate to severe canal narrowing with only two lumbar MRIs were athletics and weightlifting, while those with only one MRI were judo, rugby, water polo, boxing, sailing and tennis. Many of these sports involve physical contact.

Similarly, 14 of the spine MRIs (13\%) demonstrated moderate to severe neural foraminal narrowing, including 7 lumbar MRIs and 7 cervical MRIs. Sports with positive spine MRIs showing moderate to severe neural foraminal narrowing included athletics (four lumbar MRIs), judo (two cervical MRIs), wrestling (two cervical MRIs) and those with one lumbar MRI each were diving, rugby, weightlifting, hockey, sailing and shooting.

One male athlete in athletics had a chronic wedge fracture at T12 seen on lumbar spine MRI. One male swimmer had a syrinx at C6.

\section{Acute spine pathology}

Four lumbar spine MRIs (4 of 107, 4\%) demonstrated acute/subacute stress reaction. One female athlete in handball had vertebral body stress reaction at L2. Two athletes had severe endplate stress reaction, including a male athlete in athletics with stress reaction at L3-L4 and a female athlete in rugby with stress reaction at L4-L5. The male athlete with stress reaction at L3-L4 also had a large Schmorl node at L4. One female weightlifter had right pars interarticularis stress reaction at L5.

There were two stress reactions, including one in the L4 pedicle of an athlete in athletics and one in the L5 pars interarticularis of a weightlifter.

Four of the MRIs $(4 \%)$ of female athletes had spondylolysis, including a football player with two levels of involvement at L4 and L5. The other three had spondylolysis at a single level, one at L3 and the others at L5. Two of these athletes had grade I anterolisthesis. The athlete with spondylolysis at L3 also had grade I/II anterolisthesis (online supplementary figure S1). 
Table 3 Incidence of positive spine MRIs in female and male athletes by sport

\begin{tabular}{|c|c|c|c|c|c|c|c|c|c|c|}
\hline \multirow[b]{2}{*}{ Sport } & \multicolumn{2}{|c|}{ Total athletes } & \multicolumn{2}{|c|}{$\begin{array}{l}\text { Athletes receiving } \\
\text { spine MRIs }\end{array}$} & \multicolumn{2}{|c|}{ Positive spine MRIs } & \multicolumn{2}{|c|}{$\begin{array}{l}\text { Frequency } \\
\text { (positive MRIs/ } \\
\text { athletes receiving } \\
\text { spine MRIs) (\%) }\end{array}$} & \multicolumn{2}{|c|}{$\begin{array}{l}\text { Incidence } \\
\text { (positive MRIs/total } \\
\text { athletes } \times 100 \text { ) }\end{array}$} \\
\hline & Female & Male & Female & Male & Female & Male & Female & Male & Female & Male \\
\hline Aquatics-diving & 68 & 67 & 4 & 2 & 1 & 2 & 25 & 100 & 1.47 & 3.0 \\
\hline Aquatics-swimming & 414 & 487 & 2 & 2 & 0 & 1 & 0 & 50 & 0 & 0.2 \\
\hline Aquatics-water polo & 104 & 154 & 0 & 1 & 0 & 1 & 0 & 100 & 0 & 0.6 \\
\hline Archery & 64 & 64 & 0 & 1 & 0 & 1 & 0 & 100 & 0 & 1.6 \\
\hline Athletics & 1140 & 1227 & 22 & 9 & 11 & 4 & 50 & 44 & 1.0 & 0.3 \\
\hline Badminton & 86 & 86 & 0 & 1 & 0 & 0 & 0 & 0 & 0 & 0 \\
\hline Beach volleyball & 48 & 48 & 1 & 0 & 0 & 0 & 0 & 0 & 0 & 0 \\
\hline Boxing & 36 & 250 & 1 & 3 & 0 & 1 & 0 & 33 & 0 & 0.4 \\
\hline Canoe-sprint & 91 & 157 & 0 & 1 & 0 & 0 & 0 & 0 & 0 & 0 \\
\hline Cycling-mountain biking & 30 & 50 & 1 & 0 & 1 & 0 & 100 & 0 & 3.3 & 0 \\
\hline Equestrian & 75 & 125 & 0 & 1 & 0 & 0 & 0 & 0 & 0 & 0 \\
\hline Fencing & 104 & 100 & 1 & 1 & 0 & 1 & 0 & 100 & 0 & 1.0 \\
\hline Football & 216 & 287 & 1 & 1 & 1 & 0 & 100 & 0 & 0.5 & 0 \\
\hline Gymnastics & 210 & 112 & 5 & 1 & 0 & 1 & 0 & 100 & 0 & 0.9 \\
\hline Handball & 168 & 167 & 1 & 1 & 1 & 1 & 100 & 100 & 0.6 & 0.6 \\
\hline Hockey & 192 & 192 & 2 & 1 & 2 & 0 & 100 & 0 & 1.0 & 0 \\
\hline Judo & 153 & 237 & 2 & 6 & 1 & 4 & 50 & 67 & 0.7 & 1.7 \\
\hline Rowing & 215 & 331 & 3 & 0 & 1 & 0 & 33 & 0 & 0.5 & 0 \\
\hline Rugby & 144 & 147 & 1 & 0 & 1 & 0 & 100 & 0 & 0.7 & 0 \\
\hline Sailing & 163 & 217 & 1 & 1 & 1 & 1 & 100 & 100 & 0.6 & 0.5 \\
\hline Shooting & 151 & 239 & 0 & 3 & 0 & 1 & 0 & 33 & 0 & 0.4 \\
\hline Table tennis & 86 & 86 & 0 & 2 & 0 & 1 & 0 & 50 & 0 & 1.6 \\
\hline Tennis & 94 & 105 & 0 & 2 & 0 & 2 & 0 & 100 & 0 & 1.9 \\
\hline Triathlon & 54 & 55 & 1 & 0 & 1 & 0 & 100 & 0 & 1.9 & 0 \\
\hline Volleyball & 144 & 144 & 3 & 0 & 1 & 0 & 33 & 0 & 0.7 & 0 \\
\hline Weightlifting & 103 & 153 & 3 & 3 & 2 & 2 & 68 & 67 & 1.9 & 1.3 \\
\hline Wrestling & 114 & 235 & 0 & 2 & 0 & 2 & 0 & 100 & 0 & 0.9 \\
\hline Others & 622 & 663 & 0 & 0 & 0 & 0 & 0 & 0 & 0 & 0 \\
\hline Total & 5089 & 6185 & 55 & 45 & 25 & 26 & 45 & 58 & 0.5 & 0.4 \\
\hline
\end{tabular}

Five of the spine MRIs (5\%) showed acute/subacute muscle injuries. All these injuries occurred in female athletes. Psoas muscle injury was seen in athletics. Two unilateral posterior paraspinal muscle injuries were seen in judo and athletics. Two bilateral posterior paraspinal muscle injuries were detected in cycling and volleyball.

\section{DISCUSSION}

A significant number of the athletes were found to have advanced spinal disease, with 52 of the 100 athletes (52\%) who had spine MRI demonstrating moderate to severe spinal pathology. Therefore, approximately 1 athlete per 200 individuals participating in the 2016 Summer Olympics

Table 4 Utilisation of each type of spine MRI by athletes by continent

\begin{tabular}{|c|c|c|c|c|c|c|}
\hline Type of spine MRI & Africa & Americas & Asia & Europe & Oceania & Refugee \\
\hline Cervical & 1 & 3 & 4 & 12 & 1 & 0 \\
\hline Thoracic & 0 & 0 & 0 & 6 & 0 & 0 \\
\hline Lumbar & 18 & 13 & 8 & 37 & 4 & 0 \\
\hline Total & 19 & 16 & 12 & 55 & 5 & 0 \\
\hline
\end{tabular}




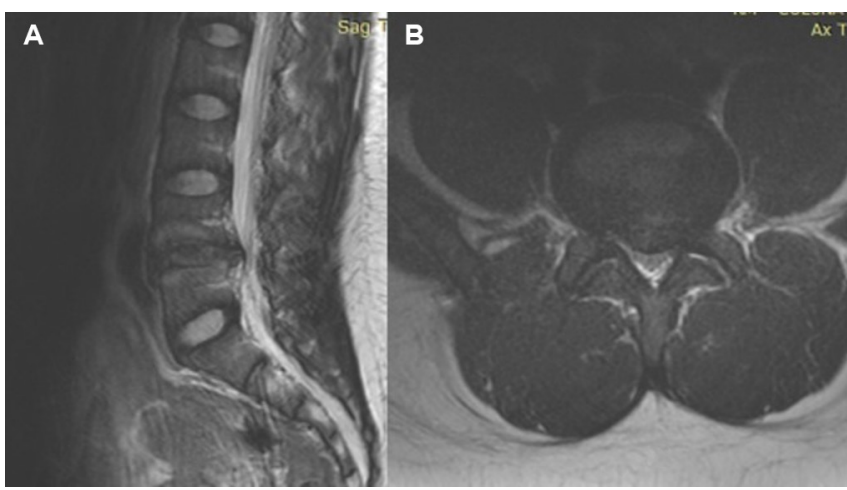

Figure $1 \mathrm{MRI}$ of a female rugby player in her 30s demonstrates Pfirrmann type IV degenerative disc changes at L4-L5 with endplate oedema (arrowheads) and a disc protrusion (arrow) seen on the sagittal and axial T2weighted images $(A, B)$, contributing to moderate to severe canal narrowing.

had advanced spine disease on MRI. Mild degenerative changes were not included in this study; a conservative approach was used for the evaluation.

At the 2012 London Games, 1283 diagnostic and interventional procedures were performed, including 674 MRIs of which 104 were of the spine. ${ }^{11}$ Although more athletes participated in the 2016 Rio Games, only 607 MRIs were performed, ${ }^{1}$ but the number of spine MRIs was slightly higher at 107 .

\section{Rate and incidence of pathology by sport}

While athletes participating in athletics had the highest overall use of spinal MRI (31 athletes), aquatic diving had the highest sport-specific rates of spinal pathology, with one positive study per 33 divers (135 divers, four MRIs). This increased rate was seen in female and male aquatic divers alike. All spinal pathologies detected in divers involved the lumbar spine, with Pfirrmann grade IV or $\mathrm{V}$ degenerative disc disease and/or moderate to severe neural foraminal narrowing detected. ${ }^{10}$ The nature of these pathologies is likely chronic and may be related to the repetitive contortion, bending and twisting of the lumbar spine that a diver must perform while plunging 3-10 $\mathrm{m}$ into the water.

Weightlifting had the second highest sport-specific rate of spinal pathology, with one positive case per 63 weightlifters (256 weightlifters, four MRIs). All positive studies seen in weightlifters were of the lumbar spine. Pfirrmann grade IV or V degenerative disc disease and/or moderate to severe canal narrowing were the most common spinal pathologies. ${ }^{10}$ Spinal stenosis can lead to a wide variety of neurological disorders. These pathologies are likely chronic in nature and may be secondary to lifting technique. Adequate precautions by focusing on improved training and lifting techniques should be considered to prevent this type of spinal pathology.

Other sports with notable spinal pathologies include judo (390 athletes) and athletics (2367 athletes). Five of the judo participants, or nearly 1 in 77 , and 15 of those in athletics, or 1 in 167 , had moderate to severe spinal pathology. Judo involves throwing and striking opponents, which may lead to overuse issues and trauma for the athlete. Athletics involves speed and strength with significant risk of overuse and acute injuries.

\section{Rate and incidence of pathology by age}

Athletes over 30 years old had higher rates of moderate to severe spinal pathology on MRI, with 1 athlete per 120 (24 out of 2910) demonstrating moderate to severe spinal disease. One athlete per 333 (27 out of 7753) between 20 and 29 years of age demonstrated moderate to severe spinal pathology. Only 1 of the 611 athletes under 20 years of age demonstrated moderate to severe spinal pathology. As previous studies have demonstrated, high-level athletes are more commonly affected by disc degeneration than non-athletes. ${ }^{12}$ The increased rate with age is likely the result of accumulation and progression of chronic injuries; however, these athletes may be prone to more acute injuries as well.

The lumbar spine was the most frequently imaged portion of the spine on MRI, accounting for 80 of the 107 spine MRIs. The highest number of positive lumbar spine studies was seen in athletics, with 12 athletes demonstrating Pfirrmann grade IV or $\mathrm{V}$ degenerative disc disease, 2 demonstrating moderate to severe canal narrowing and 4 demonstrating moderate to severe neural foraminal narrowing. Neural foraminal stenosis can lead to radiculopathy, with nerve compression and increasing pain symptoms.

European athletes had more spinal MRIs during the Rio Games than the rest of the world combined. There are likely many factors influencing this disproportionate utilisation of spinal MRI, but most likely it is the result of the medical staff and trainers' input into who is scanned.

Acute spine pathologies, such as stress reaction oedema and muscle injury, were more commonly seen in female than male athletes. While there is no clear explanation for this predominance, all of these injuries involved the lumbar region, suggesting that chronic pathologies of the lumbar spine may first start as other injuries and progress to degenerative changes.

One question is how elite athletes, such as those participating in the Olympics, can compete at the highest level with the kind of severe spinal pathology seen in our study. A previous study found that athletes with low back pain perceive less impairment compared with non-athletes. ${ }^{13}$ Perhaps, elite athletes have different coping mechanisms for pain to endure the demands of elite competition in which they place their body at risk for acute or overuse injury.

Spinal disease was detected at single time points during the Olympics, but neither prior studies nor follow-up imaging were available to determine acuity versus chronicity of several of the spinal pathologies identified. Lack of clinical correlation is also a limitation. Another limitation is that we do not know if other athletes had spine injuries and did not come to the IOC imaging facility for MRI. 


\section{CONCLUSIONS}

A significant number of athletes demonstrated advanced spinal disease on MRI during the 2016 Summer Olympics in Rio de Janeiro, with approximately 1 athlete per 200 demonstrating moderate to severe spinal pathology. The lumbar spine was the most commonly affected site of disease. Many of the Olympic sports rely on strength, speed, force, bending and twisting. Even with excellent preparation and training, the spine is at risk for moderate to severe injury. The highest rates of spine injury were seen in women and athletes over 30 years old. Recognition of these risks is important, as there should be efforts to avoid the long-term sequelae of spinal pathology. Spine-conscious training, routines and manoeuvres are recommended to prevent the development and progression of these acute and chronic spinal pathologies. Our hope is to better direct injury prevention strategies in future Olympic games.

\section{Author affiliations \\ ${ }^{1}$ Department of Radiology, Boston University School of Medicine, Boston, Massachusetts, USA \\ ${ }^{2}$ Department of Radiology, Mercy Catholic Medical Center, Darby, Pennsylvania, USA ${ }^{3}$ Medical and Scientific Department, International Olympic Committee, Lausanne, Switzerland \\ ${ }^{4}$ Department of Sports Medicine, Oslo Sports Trauma Research Center, Norwegian School of Sport Sciences, Oslo, Norway \\ ${ }^{5}$ Department of Orthopedic Surgery, Oslo University Hospital, University of Oslo, Oslo, Norway \\ ${ }^{6}$ Department of Radiology, University of Erlangen-Nuremberg, Erlangen, Germany \\ ${ }^{7}$ Department of Radiology, Stony Brook Medicine, Stony Brook, New York, USA \\ ${ }^{8}$ Department of Sports Medicine, National Institute of Sports (INSEP), Paris, France \\ ${ }^{9}$ Department of Radiology, Saint-Antoine Hospital, University Paris VI, Paris, France}

Acknowledgements We thank $10 \mathrm{C}$ members and all staff of Olympic Village imaging center and sports physicians/radiologists who provided clinical service.

Competing interests AG is the president of Boston Imaging Core Lab (BICL) and a consultant to Merck Serono, AstraZeneca, Pfizer, GE Healthcare, OrthoTrophix, Sanofi and TissueGene. FWR, AZM and MDC are shareholders of BICL. LE is a consultant to Arthrex and Smith \& Nephew. DH, MAK, MSW and MJ have nothing to disclose.

Ethics approval This study obtained ethical approval from Medical Research Ethics Committee of the South-Eastern Norway Regional Health Authority (2011/388) and from Boston University (IRB no: H-36593).
Provenance and peer review Not commissioned; externally peer reviewed.

Open Access This is an Open Access article distributed in accordance with the Creative Commons Attribution Non Commercial (CC BY-NC 4.0) license, which permits others to distribute, remix, adapt, build upon this work non-commercially, and license their derivative works on different terms, provided the original work is properly cited and the use is non-commercial. See: http://creativecommons.org/ licenses/by-nc/4.0/

(C) Article author(s) (or their employer(s) unless otherwise stated in the text of the article) 2018. All rights reserved. No commercial use is permitted unless otherwise expressly granted.

\section{REFERENCES}

1. Guermazi A, Hayashi D, Jarraya M, et al. Imaging depicted sports injuries at Rio de Janeiro 2016 Summer Olympic Games: Retrospective analysis of utilization of diagnostic imaging services. Radiology; 2017 (Accepted).

2. Soligard T, Steffen K, Palmer D, et al. Sports injury and illness incidence in the Rio de Janeiro 2016 Olympic Summer Games: A prospective study of 11274 athletes from 207 countries. Br J Sports Med 2017;51:1265-71.

3. Junge A, Engebretsen L, Mountjoy ML, et al. Sports injuries during the Summer Olympic Games 2008. Am J Sports Med 2009;37:2165-72.

4. Engebretsen L, Steffen K, Alonso JM, et al. Sports injuries and illnesses during the Winter Olympic Games 2010. Br J Sports Med 2010;44:772-80.

5. Engebretsen L, Soligard T, Steffen $\mathrm{K}$, et al. Sports injuries and illnesses during the London Summer Olympic Games 2012. Br J Sports Med 2013;47:407-14.

6. Soligard T, Steffen K, Palmer-Green D, et al. Sports injuries and illnesses in the Sochi 2014 Olympic Winter Games. Br J Sports Med 2015;49:441-7.

7. Ong A, Anderson J, Roche J. A pilot study of the prevalence of lumbar disc degeneration in elite athletes with lower back pain at the Sydney 2000 Olympic Games. Br J Sports Med 2003;37:263-6.

8. Jenis LG, An HS. Spine update. Lumbar foraminal stenosis. Spine 2000;25:389-94.

9. Guermazi A, Roemer FW, Robinson P, et al. Imaging of Muscle injuries in sports medicine: sports imaging series. Radiology 2017;282:646-63.

10. Pfirrmann CW, Metzdorf A, Zanetti M, et al. Magnetic resonance classification of lumbar intervertebral disc degeneration. Spine 2001;26:1873-8.

11. Bethapudi S, Budgett R, Engebretsen L, et al. Imaging at London 2012 summer Olympic Games: analysis of demand and distribution of workload. Br J Sports Med 2013;47:850-6.

12. Swärd L, Hellström M, Jacobsson B, et al. Disc degeneration and associated abnormalities of the spine in elite gymnasts. A magnetic resonance imaging study. Spine 1991;16:437-43.

13. Heidari $\mathrm{J}$, Mierswa $\mathrm{T}$, Hasenbring $\mathrm{M}$, et al. Low back pain in athletes and non-athletes: a group comparison of basic pain parameters and impact on sports activity. Sport Sci Health 2016;12:297-306. 


\section{Correction: Evaluation of spine MRIs in athletes participating in the Rio de Janeiro 2016 Summer Olympic Games}

Michael S Wasserman, Ali Guermazi, Mohamed Jarraya, et al. Evaluation of spine MRIs in athletes participating in the Rio de Janeiro 2016 Summer Olympic Games. BMJ Open Sport Eै Exercise Medicine 2018;4:e000335. DOI: 10.1136/bmjsem-2017-000335.

The fifth author's surname was incorrectly spelt, it is Abdalkader (not AbdelKader).

Open Access This is an Open Access article distributed in accordance with the Creative Commons Attribution Non Commercial (CC BY-NC 4.0) license, which permits others to distribute, remix, adapt, build upon this work non-commercially, and license their derivative works on different terms, provided the original work is properly cited and the use is non-commercial. See: http://creativecommons.org/licenses/by-nc/4.0/

(c) Article author(s) (or their employer(s) unless otherwise stated in the text of the article) 2018. All rights reserved. No commercial use is permitted unless otherwise expressly granted.

BMJ Open Sport Exerc Med 2018;4:e000335corr1. doi:10.1136/bmjsem-2017-000335corr1

A) Check for updates 